\title{
Hypertrophy of mature Xenopus muscle fibres in culture induced by synergy of albumin and insulin
}

\author{
R. T. Jaspers • B. J. van Beek-Harmsen • \\ M. A. Blankenstein • G. Goldspink • P. A. Huijing • \\ W. J. van der Laarse
}

Received: 28 February 2008 /Revised: 17 March 2008 /Accepted: 17 March 2008 / Published online: 21 May 2008

(C) The Author(s) 2008

\begin{abstract}
The aim of this study was to investigate effects of albumin and insulin separately as well as in combination on mature muscle fibres during long-term culture. Single muscle fibres were dissected from $\mathrm{m}$. iliofibularis of Xenopus laevis and attached to a force transducer in a culture chamber. Fibres were cultured in a serum-free medium at slack length (mean sarcomere length $2.3 \mu \mathrm{m}$ ) for 8 to 22 days. The medium was supplemented with (final concentrations): (1) bovine insulin $(6 \mathrm{nmol} / \mathrm{L}$ or 200 $600 \mathrm{nmol} / \mathrm{L}$ ), (2) $0.2 \%$ bovine albumin or (3) $0.2 \%$ bovine albumin in combination with insulin $(120 \mathrm{nmol} / \mathrm{L})$. In
\end{abstract}

\footnotetext{
R. T. Jaspers $(\square) \cdot$ P. A. Huijing

Research Institute Move, Faculty of Human Movement Sciences, VU University Amsterdam,

van der Boechorststraat 9,

1081 BT Amsterdam, The Netherlands

e-mail: r.jaspers@fbw.vu.nl
}

B. J. van Beek-Harmsen - W. J. van der Laarse

Department of Physiology, Institute for Cardiovascular Research, VU University Medical Center,

Amsterdam, The Netherlands

M. A. Blankenstein

Department of Clinical Chemistry, VU University Medical Center, Amsterdam, The Netherlands

G. Goldspink

Molecular Tissue Repair Unit, Department of Surgery,

Royal Free and University College Medical School,

University College,

London, UK

\section{P. A. Huijing}

Integrated Biomedical Engineering for Restoration of Human

Function, Biomedisch Technologisch Instituut,

Universiteit Twente,

Enschede, The Netherlands culture medium with insulin, $50 \%$ of the muscle fibres became in-excitable within 7-12 days, whereas the other $50 \%$ were stable. Caffeine contractures of in-excitable muscle fibres produced $80.4 \pm 2.4 \%$ of initial peak tetanic force, indicating impaired excitation-contraction $(\mathrm{E}-\mathrm{C})$ coupling in in-excitable fibres. In the presence of albumin, all cultured muscle fibres were stable for at least 10 days. Muscle fibres cultured in medium with insulin or albumin exclusively did not hypertrophy or change the number of sarcomeres in series. In contrast, muscle fibres cultured with both albumin and insulin showed an increase in tetanic force and fibre cross-sectional area of $19.6 \pm 2.8 \%$ and $32.5 \pm 4.9 \%$, respectively, (means \pm SEM.; $P=0.007$ ) after $16.3 \pm 1.7$ days, whereas the number of sarcomeres in series remained unchanged. We conclude that albumin prevents muscle fibre damage and preserves $\mathrm{E}-\mathrm{C}$ coupling in culture. Furthermore, albumin is important in regulating muscle fibre adaptation by a synergistic action with growth factors like insulin.

Keywords Adaptation · Albumin · Hypertrophy Insulin . Skeletal muscle fibre

\section{Introduction}

Chronic catabolic conditions (e.g. chronic heart failure, chronic obstructive pulmonary disease, cancer and HIV) are characterised by severe muscle wasting causing limited mobility of millions of patients [40]. Prevention of muscle atrophy and induction hypertrophy requires insight in the mechanisms regulating protein synthesis and breakdown. Many genes and physiological stimuli are involved in the regulation of adaptation of muscle size [14, 2, 19]. Of these, insulin and insulin-like growth factors (IGFs) are key 
regulators of muscle protein synthesis and degradation [12, 14, 15]. The mechanisms by which insulin and IGFs stimulate the synthesis and inhibit the degradation of muscle proteins are subject of controversy (cf. [44, 22, 10]). A major reason for this is that the effects of insulin and insulin-like factors depend strongly on several other factors [29]. Insulin and IGF-1 activate the phosphatidylinositol 3-Kinase (PI3K)-Akt-mammalian target of rapamycin (mTOR) pathway $[29,14]$. In myoblasts, activity of this pathway is transiently increased, indicating that exposure time is a determinant of the effects of insulin and IGFs [23]. The availability of amino acids as well as the type and magnitude of exercise are important for the signalling effects of insulin on mRNA translation [29]. The ability of IGF-1 to induce proliferation of myoblast is critically dependent on unknown serum components [12].

Because unravelling how insulin and IGFs interact with other factors and regulate adaptation of muscle phenotype requires independent manipulation of the regulators and signalling pathways, we developed a serum-free culture system for longitudinal study (months) of mature, single Xenopus muscle fibres [35, 28].

For initial experiments, $50 \%$ of cultured muscle fibres (five out of ten) produced stable peak tetanic forces after electrical stimulation for at least 2 weeks [26]. Tetanic force of the other fibres was reduced by $>50 \%$ during the first week. These fibres could only be activated by caffeine, indicating failure of excitation-contraction $(\mathrm{E}-\mathrm{C})$ coupling. Despite supra-physiological insulin concentrations in the culture medium, no hypertrophy or adaptation of the number of sarcomeres in series occurred [26], even when the fibres were cultured for more than 3 weeks at $5 \%$ above slack length $[28,27]$. These observations indicate that insulin alone is not sufficient to induce muscle fibre hypertrophy despite availability of amino acids. Apparently, for active insulin signalling in serum-free cultured mature muscle fibres, at least one additional serum component is required. A similar conclusion was reached previously with respect to IGF-1 signalling in myoblasts [12]. A plasma protein that could be essential in insulin-IGF-1 signalling may be albumin because: (a) albumin is a carrier of hormones, growth factors and amino acids [37, 45], (b) reduced plasma albumin levels during ageing are associated with a loss of muscle mass and decrease of maximum active muscle force [3, 46], (c) culture of myotubes at high strain stimulates hypertrophy as well as the uptake of albumin from the extracellular fluid [1]. In addition, albumin may also prevent muscle fibre damage because albumin is: (d) an extracellular antioxidant [18, 37], (e) capable of preserving the calcium-pump activity of the sarcoplasmic reticulum of cardiomyocytes [5] and (f) increasing the viability of $\mathrm{C} 2 \mathrm{C} 12$ cells [8]. Based on these results, we hypothesise that albumin preserves $\mathrm{E}-\mathrm{C}$ coupling in cultured muscle fibres and that albumin is involved in the induction of muscle hypertrophy. To test these hypotheses, we investigated the effects of albumin and insulin separately, as well as in combination on mature, single muscle fibres during long-term culture.

\section{Materials and methods}

Animals and culture system

Treatment of animals was in accordance with the guidelines and regulations concerning animal welfare and experimentation set forth by Dutch law and approved by the Committee on Ethics of Animal Experimentation at the VU University Amsterdam. In brief, after cooling in ice water for about $15 \mathrm{~min}$, Xenopus laevis (females, 9-10 cm body length, $n=22$ ) were killed by decapitation and both iliofibularis muscles were excised. The muscles were allowed to recover for $1 \mathrm{~h}$ in sterilised $(0.22-\mu \mathrm{m}$ filter), oxygenated Ringer solution $(\mathrm{NaCl}, 116.5 \mathrm{mM} ; \mathrm{KCl}$, $2.0 \mathrm{mM} ; \mathrm{CaCl}_{2}, 1.9 \mathrm{mM} ; \mathrm{NaH}_{2} \mathrm{PO}_{4}, 2.0 \mathrm{mM}$; ethylene glycol tetraacetic acid, $0.1 \mathrm{mM} ; \mathrm{pH}$ 7.2). After recovery, both muscles were transferred to aseptic dissection troughs [32]. Highly oxidative single muscle fibres (type 2/3 according to the classification of Lännergren and Smith [32]) were carefully dissected under aseptic conditions using fine-tipped forceps and scissors under observation through a microscope fitted with dark-field illumination (one or two fibres per animal). Small platinum hooks were tied to the trimmed tendons using 20 - $\mu \mathrm{m}$-diameter sterile polyamide thread. The platinum hooks and tools for dissection were sterilised using $70 \%$ ethanol. Before transferring the isolated fibre to the culture chamber, fibre diameters and the number of sarcomeres in series were determined (see below).

All parts of the culture chamber [35] were sterilised using $70 \%$ ethanol. The fibre was mounted at the target length between a force transducer (AE801, SensoNor, Horten, Norway) and an adjustable rod (Fig. 1).

The chamber contained $0.8 \mathrm{ml}$ of culture medium. The stock solution of the culture medium consisted of $66 \%$ Dulbecco's modified Eagle's medium/F12 (GibcoBRL, Life Technologies, Breda, The Netherlands) with $100 \mathrm{U} \mathrm{mL}^{-1}$ penicillin per $100 \mu \mathrm{g} \mathrm{mL} \mathrm{m}^{-1}$ streptomycin (GibcoBRL), $5 \mathrm{mM}$ sodium phosphate, $1 \mathrm{mM}$ creatine (Sigma-Aldrich, Zwijndrecht, The Netherlands), $0.5 \mathrm{mM}$ L-carnitine (SigmaAldrich, Zwijndrecht, The Netherlands). To investigate the effects of insulin, albumin and their combination, the stock medium was supplemented with one of the following agents: (1) $1 \mu \mathrm{g} \mathrm{mL}^{-1}$ bovine insulin (Serva, Heidelberg, Germany), (2) $10 \mu \mathrm{g} \mathrm{mL}^{-1}$ bovine insulin, (3) $0.2 \%$ bovine serum albumin (BSA; Sigma-Aldrich, Zwijndrecht, The 


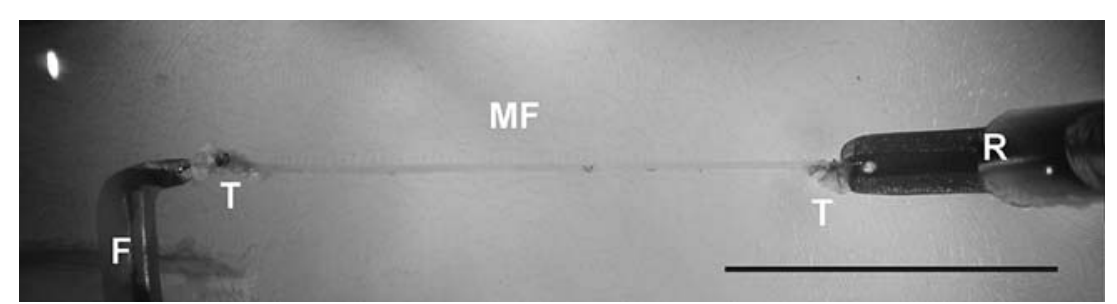

Fig. 1 Single muscle fibre in culture. A single Xenopus laevis muscle fibre $(M F)$ is attached via trimmed tendons $(T)$ to platinum hooks which are attached to a force transducer $(F)$ and to a movable rod $(R)$. Bar indicates $5 \mathrm{~mm}$

Netherlands) and (4) both $1 \mu \mathrm{g} \mathrm{mL} \mathrm{m}^{-1}$ bovine insulin and $0.2 \%$ BSA.

As insulin may bind to glass and tubing, the final insulin concentration in the culture chamber was measured using an immunoradiometric assay (Biosource Europe, Nivelles, Belgium). To determine the actual insulin concentration in the culture medium during the culture, human insulin (Sigma-Aldrich) was used as a model for bovine insulin. The final insulin concentration in the culture chamber when $1 \mu \mathrm{g} \mathrm{mL} \mathrm{m}^{-1}$ bovine insulin was supplemented was $6.3 \pm$ $1.8 \mathrm{nmol} / \mathrm{L}$ (mean $\pm \mathrm{SEM}$ ), which is 35 times lower than the value in the stock solution $(170 \mathrm{nmol} / \mathrm{L})$. Compared to the Xenopus plasma insulin concentration of $10.46 \mu \mathrm{U} / \mathrm{mL}$ [36], the insulin concentration in the culture chamber is about 1,000-fold higher (assuming an insulin activity of $28 \mathrm{U} / \mathrm{mg}$ ). When $10 \mu \mathrm{g} \mathrm{mL}^{-1}$ bovine insulin was added to the stock culture medium, the insulin concentration in the culture chamber was between 200 and $400 \mathrm{nmol} / \mathrm{L}$. Addition of $1 \mu \mathrm{g} \mathrm{mL} \mathrm{m}^{-1}$ insulin to a stock solution containing a $0.2 \%$ BSA yielded an insulin concentration of $121.4 \pm 2.9 \mathrm{nmol} / \mathrm{L}$ in the culture chamber.

Before culture, the number of sarcomeres in series and fibre cross-sectional area (CSA) were determined as described previously [26]. In the dissection chamber, fibres were stretched to just over slack length. Sarcomere length was determined every millimeter along the length of the fibre using laser diffraction and the mean sarcomere length was calculated. Subsequently, muscle fibre length was adjusted to a length corresponding to a mean sarcomere length of $2.3 \mu \mathrm{m}\left(1_{2.3 \mu \mathrm{m}}\right.$, i.e. approximately fibre slack length). At this fibre length, the CSA was determined by measuring the smallest and largest diameters of the fibre at three positions along the length of the muscle fibre. The CSA was calculated assuming an elliptical cross section and muscle fibre CSA was taken as the mean of these three values.

After these measurements, the fibres were mounted in the culture chamber and length was adjusted to $1_{2.3} \mu \mathrm{m}$. The culture chamber was transferred to an incubator kept at $20^{\circ} \mathrm{C}$ and tubing for gas and culture medium supply were connected. Fresh culture medium was continuously pumped through the chamber at a rate of about $0.5 \mathrm{~mL} \mathrm{~h}^{-1}$ and was equilibrated with air, containing $2.4 \% \mathrm{CO}_{2}$. Final $\mathrm{pH}$ was 7.6 and osmolarity was $235-250 \mathrm{mOsm} \mathrm{kg}^{-1}$. The oxygen tension of the culture medium sampled from the chamber was 120 to $130 \mathrm{mmHg}$.

During subsequent days, twitch and tetanic forces were measured once every $24 \mathrm{~h}$. The fibre was stimulated (0.4-ms biphasic current pulses, 1.25 times threshold voltage) via platinum plate electrodes flanking the full length of the fibre to produce two twitches, one tetanus $(50 \mathrm{~Hz}, 260-\mathrm{ms}$ duration) and a post-tetanic twitch $(300 \mathrm{~ms}$ after the last pulse of the tetanus). After culture, muscle fibres were again transferred to the dissection chamber filled with Ringer solution and the fibre CSA as well as the number of sarcomeres in series was determined again.

\section{Histochemistry}

After culture, fibres were embedded at $\mathrm{l}_{2.3 \mu \mathrm{m}}$ in gelatin Ringer $(15 \%(w / v), \mathrm{pH} 7.2)$, and frozen in liquid nitrogen. Within 3 days after freezing in liquid nitrogen, cross sections (10 and $16 \mu \mathrm{m}$ thick) were cut using a cryostat at $-20^{\circ} \mathrm{C}$ and mounted on glass slides coated with Vectabond (Vector Laboratories, Burlingame, USA). The 16- $\mu$ m-thick sections were immediately assayed for succinate dehydrogenase (SDH, see below). The $10-\mu \mathrm{m}$ sections were dried and subsequently stored at $-80^{\circ} \mathrm{C}$ until further use (3-12 months).

The following stainings were performed for the following variables:

Myofibrillar adeno triphosphatase (ATPase) activity was determined as described in detail previously [51]. Sections (10 $\mu \mathrm{m}$ thick) were air-dried and then incubated for calciumstimulated myofibrillar ATPase for $10 \mathrm{~min}$ at $20^{\circ} \mathrm{C}$. The incubation medium consisted of $83-\mathrm{mM}$ Tris-maleate buffer, 5.6 $\mathrm{mM} \mathrm{Pb}\left(\mathrm{NO}_{3}\right)_{2}, 10 \mathrm{mM} \mathrm{CaCl}{ }_{2}$ and $9 \mathrm{mM} \mathrm{Na}_{2} \mathrm{ATP}, \mathrm{pH} .7 .2$. After the incubation, the sections were developed in $\mathrm{Na}_{2} \mathrm{~S}$.

Glycogen contents in the muscle fibres were determined with the periodic acid-Schiff (PAS) staining reaction [55, 52]. Sections (10 $\mu \mathrm{m}$ thick) were air-dried and fixed in $4 \%$ formaldehyde in $20 \mathrm{ml} 0.2 \mathrm{M}$ imidazol and $180 \mathrm{ml}$ acetone. Subsequently, sections were oxidised in $44 \mathrm{mM}$ periodic acid for $30 \mathrm{~min}$ in a water bath at $20^{\circ} \mathrm{C}$. After oxidation, sections were briefly washed in $0.1 \mathrm{M} \mathrm{HCl}$, stained with Schiff's reagent for $25 \mathrm{~min}$ at $20^{\circ} \mathrm{C}$.

Neutral lipid content was examined using oil red $\mathrm{O}$ staining [31]. Sections (10 $\mu \mathrm{m}$ thick) were air-dried and 
fixed in phosphate-buffered 4\% formaldehyde (Merck, Amsterdam, The Netherlands) for $1 \mathrm{~h}$ and washed three times for $30 \mathrm{~s}$ in water. Sections were incubated for $30 \mathrm{~min}$ in a $60 \%(v / v)$ oil red O stock solution. The oil red O stock solution consisted of $500 \mathrm{mg}$ oil red O (Fluka Chemie, Zwijdrecht, The Netherlands) dissolved in $100 \mathrm{ml} 60 \%$ triethyl-phosphate $\left(\left(\mathrm{C}_{2} \mathrm{H}_{5} \mathrm{O}\right)_{3} \mathrm{PO}\right.$, Fluka Chemie). Prior to incubation, this solution was filtered through Schleicher and Schuell paper number 595 (Whatman, the Netherlands) to remove crystallised oil red $\mathrm{O}$. After incubation in oil red $\mathrm{O}$ medium, sections were washed three times for $30 \mathrm{~s}$ in water and subsequently mounted in glycerin-gelatin.

$S D H$ was determined as described by van der Laarse et al. [49]. The activity determined in this way is proportional toVO ${ }_{2 \max }$ of muscle fibres. Muscle cross sections $(16 \mu \mathrm{m}$ thick) were air-dried for $15 \mathrm{~min}$ and incubated in the dark at $20^{\circ} \mathrm{C}$ for $45 \mathrm{~min}$. The incubation medium consisted of $37.5 \mathrm{mM}$ sodium phosphate buffer, $75 \mathrm{mM}$ sodium succinate, $5 \mathrm{mM}$ sodium azide and $0.4 \mathrm{mM}$ tetranitro blue tetrazolium, $\mathrm{pH}$ 7.6.

Cytochrome c oxidase activity (CYTOX) was assayed as described by Old and Johnson [42]. Sections (10 $\mu \mathrm{m}$ thick) were air-dried and subsequently incubated for minutes in oxygenated media containing $5 \mathrm{mM}$ diaminobenzidine and $100 \mu \mathrm{M}$ cytochrome $\mathrm{c}$.

All sections were mounted in glycerin-gelatin and stored at $4^{\circ} \mathrm{C}$ in the dark until staining intensity was measured.

\section{Microdensitometry}

The absorbance values of the final reaction products in the sections were determined using a Leica DMRB microscope (Wetzlar, Germany) fitted with calibrated grey filters using different interference filters. Absorbances for SDH were determined at $660 \mathrm{~nm}\left(\mathrm{~A}_{660}\right)$, PAS myofibrillar ATPase at $550 \mathrm{~nm}\left(\mathrm{~A}_{550}\right)$, oil red $\mathrm{O}$ at $480 \mathrm{~nm}\left(\mathrm{~A}_{480}\right)$ and COTOX at $436 \mathrm{~nm}\left(\mathrm{~A}_{436}\right)$. Images were recorded with a $\times 20$ objective and a Sony XC-77CE camera (Towada, Japan) connected to an LG-3 frame grabber (Scion; Frederick, MD, USA) in an Apple Power Macintosh computer. Recorded images were analysed with the public domain programme NIH-Image V1.61 (US National Institutes of Health, available at http:// rsb.info.nih.gov/nih-image/). Grey values were converted to absorbance values per pixel using the grey filters and a third-degree polynomial fit in the calibrate option of NIHimage. Morphometry was calibrated using a slide micrometre and the set scale option in NIH-image, taking the pixel-to-aspect ratio into account.

\section{Statistics}

Up to 8 days in culture, significance of changes in tetanic force during culture and differences between the different culture media were tested by two-way analysis of variance with repeated measures on one factor. After 8 days of culture, changes in tetanic forces were tested by regression analyses for repeated measures according to [4]. Changes in muscle fibre CSA and number of sarcomeres in series were tested by paired $t$-tests. A $P$ value of less than 0.05 was considered significant. Values are presented as means \pm SEM.

\section{Results}

Excitability, tetanic force and adaptation of muscle fibre size

Figure 2 shows tetanic force recordings of individual muscle fibres during culture in the different culture media. Half of the muscle fibres (6 out of 12) cultured in medium with supplements of $1 \mu \mathrm{g} / \mathrm{ml}$ insulin exclusively (which gives a final concentration in the culture medium of $6.3 \pm$ $1.8 \mathrm{nmol} / \mathrm{L}$, see methods), became in-excitable within 7 12 days. When activated by $20 \mathrm{mM}$ caffeine, in-excitable muscle fibres produced $80.4 \pm 2.4 \%$ of the initial tetanic force. Fibres that were not tested by caffeine developed hyper-contractions and died. The excitable muscle fibres showed a mean decline of peak tetanic force of $12.4 \pm 3.4 \%$ during the first 4 days of culture (Fig. 3). Subsequently, force returned to initial values (Figs. 2a and 3). Muscle fibre CSA and the number of sarcomeres in series were unchanged (Fig. 4a and b).

Five muscle fibres cultured with BSA supplement exclusively remained electrically excitable for at least 10 days. Tetanic force remained unchanged until day 7 , after which it decreased by $0.54 \%$ per day $\pm 0.12 \%$ ( $r=$ $-0.76, P<0.0001$ ) of the initial value (Figs. 2c and 3 ). Muscle fibre CSA and number of sarcomeres in series were unchanged (Fig. 4a and b).

For five muscle fibres cultured with supplements of both $0.2 \% \mathrm{BSA}$ and $1 \mu \mathrm{g} \mathrm{mL}^{-1}$ bovine insulin, the final insulin concentration within the culture chamber was estimated to be $121.4 \pm 2.9 \mathrm{nmol} / \mathrm{L}$ (i.e. @ 20 times higher than in medium supplemented with insulin only). These fibres were electrically excitable for at least 10 days, confirming effects of albumin on preserving $\mathrm{E}-\mathrm{C}$ coupling. Tetanic force increased by $1.3 \%$ per day $\pm 0.15 \%$ of the initial value (Figs. 2d and 3). CSA of the muscle fibres increased by $32.5 \pm 4.9 \%(P=0.007)$ after $16.3 \pm 1.7$ days (Fig. $4 \mathrm{~b})$. This increase correlates with the increase in tetanic force (Spearman's rank correlation coefficient $=0.98, P<0.001$; Fig. 4c). The number of sarcomeres in series was unchanged (Fig. 4a).

To test whether the BSA + insulin-induced hypertrophy could be explained by the higher insulin concentration in 

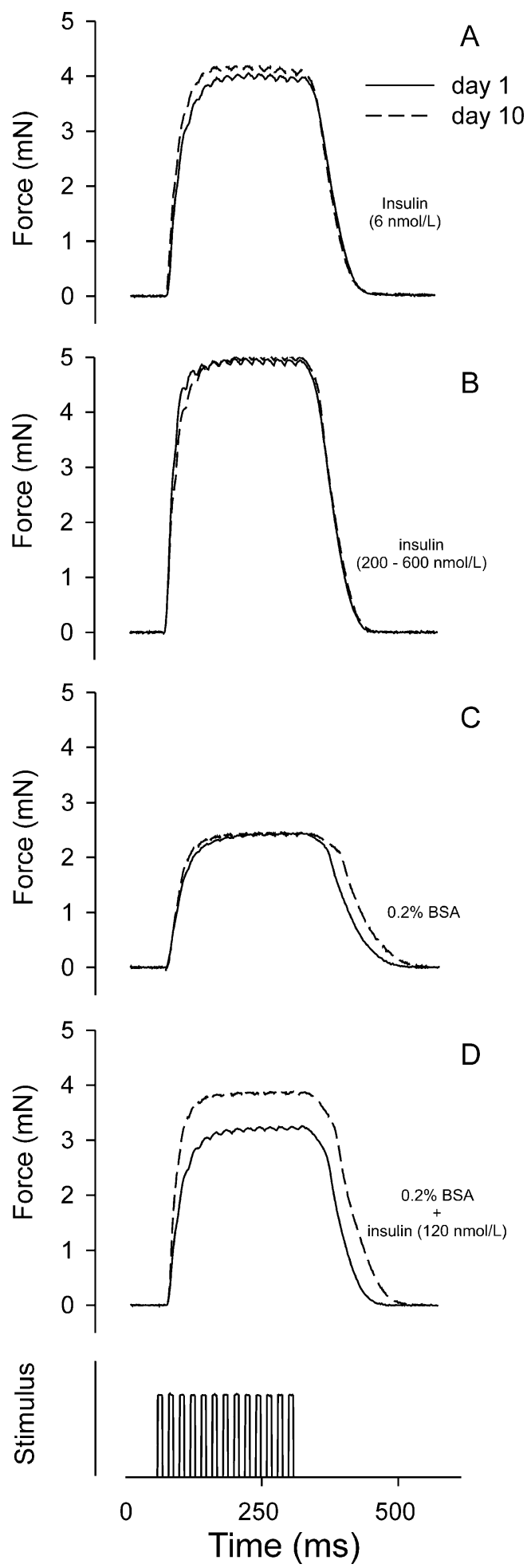

Fig. 2 Examples of tetanic forces of a muscles fibre at day 1 and 10 during culture in medium with different supplements. The muscle fibres were cultured in serum-free culture medium containing insulin and/or albumin (BSA): a medium containing $6 \mathrm{nmol} / \mathrm{L}$ insulin, b 200$600 \mathrm{nmol} / \mathrm{L}$ insulin, c $0.2 \%$ BSA, d $0.2 \%$ BSA $+120 \mathrm{nmol} / \mathrm{L}$ insulin. Stimulus pulses are indicated below the force tracings the culture chamber $(20 \times$ higher compared to insulinsupplemented exclusively), another group of muscle fibres was cultured in the presence of $200-600 \mathrm{nmol} / \mathrm{L}$ insulin for periods varying from 8 to 24 days $(n=4)$. Even at these extremely high insulin concentrations, one of these muscle fibres was in-excitable or appeared damaged within 1 week and produced a force of $91 \%$ of the initial peak tetanic force after addition of $20 \mathrm{mM}$ caffeine. The other appeared to be damaged after 1 week. Muscle fibres with unimpaired E-C coupling did not increase tetanic force (Figs. 2b and 3), the number of sarcomeres in series (Fig. 4a) or CSA (Fig. 4b). We conclude that insulin alone even at high concentrations does not induce hypertrophy or preserve $\mathrm{E}-\mathrm{C}$ coupling.

Myofibrillar ATPase activity, cytoplasmic contents of neutral lipids, glycogen and mitochondrial enzymes

In order to investigate the cause of the difference in the relative increase of tetanic force with that of the fibre CSA (i.e. increase in CSA being twice as high as the increase in tetanic force), myofibrillar ATPase activity, glycogen and neutral lipid contents, as well as mitochondrial enzyme activities were determined in cryosections of muscle fibres which had been cultured in the presence of albumin exclusively or BSA + insulin. The results of the different assays are shown in Fig. 5. Myofibrillar ATPase activity was measured to determine whether the synthesised myosin heavy chains were functional. The other assays were performed to determine whether the changes in CSA were due to accumulation of cytoplasmic components. Figure $5 \mathrm{a}-\mathrm{c}$ show that the mean myofibrillar ATPase activity was not different between

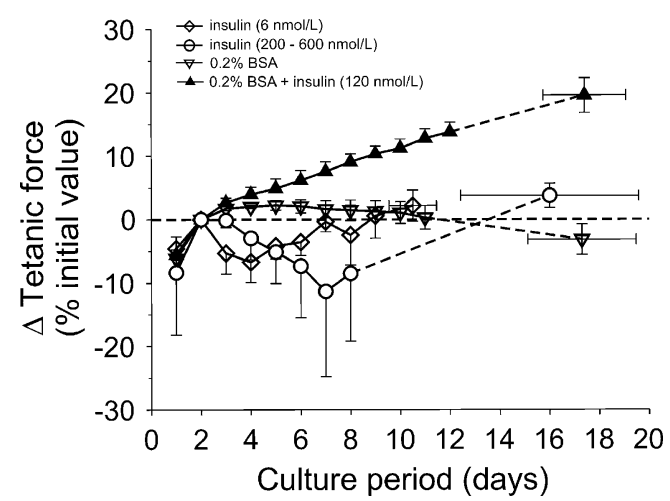

Fig. 3 Effects of albumin and insulin on the tetanic force of mature muscle fibres. Mean change $( \pm \mathrm{SEM})$ in tetanic force during culture in serum-free culture medium supplemented with insulin and/or BSA. Changes in forces are expressed as percentages of the initial tetanic forces at day 2. Fibres were cultured for periods varying from 8 to 24 days. The dotted line represents an interpolation between the mean values at the highest culture time at which all the fibres per condition are included and the mean values at the ends of culture. Note that the estimated insulin concentration in the culture chamber differs between the conditions 

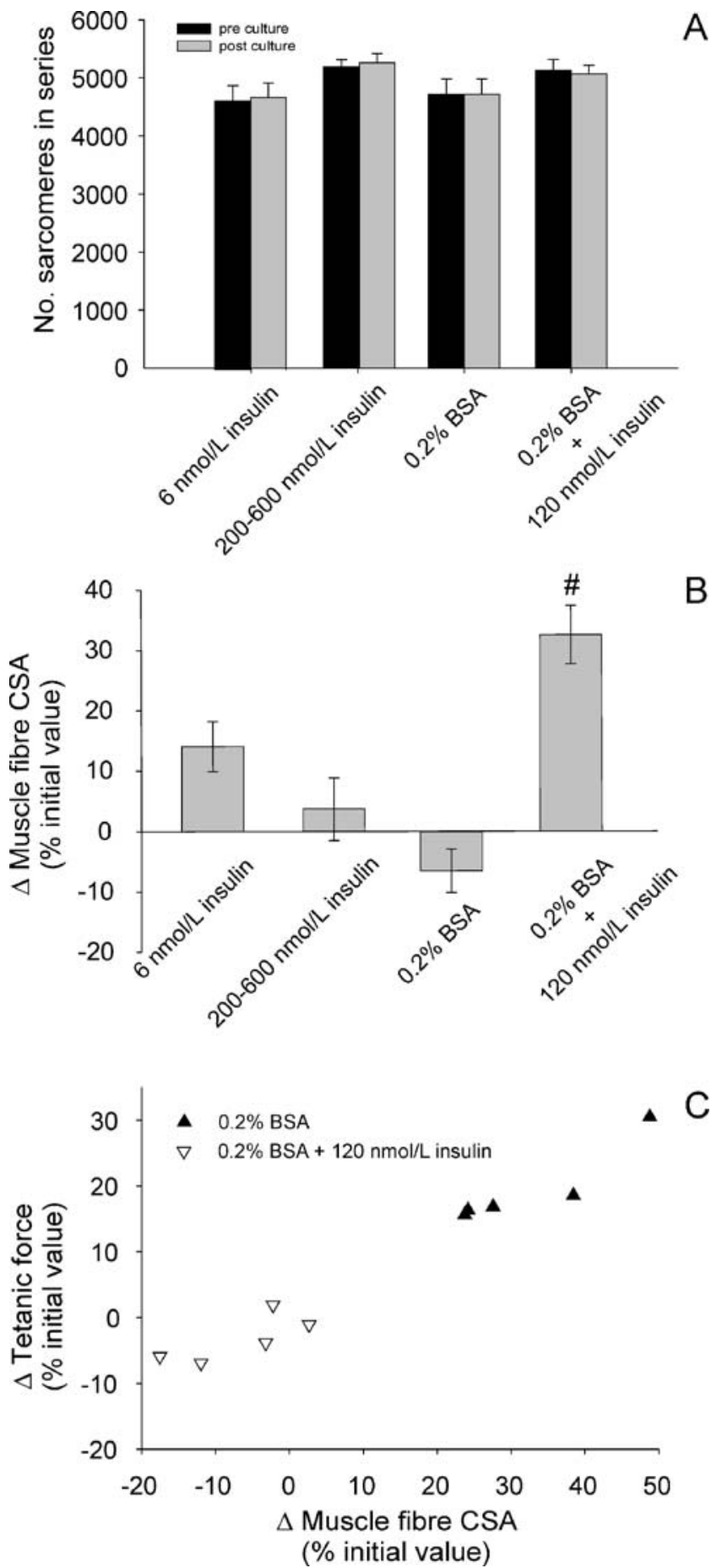

Fig. 4 Effects of albumin and insulin on the number of sarcomeres in series and CSA of mature single muscle fibres. a Pre-and post-culture mean numbers of sarcomeres in series. b Muscle fibre CSA during culture. Muscle fibre CSA was determined before and after culture. Number sign, value after culture is significantly different from the value before culture $(P<0.01)$. c The change of muscle fibre CSA correlates with the change in tetanic force. For individual muscle fibres cultured in medium with BSA only or in medium with BSA and insulin the relative change in tetanic force is expressed as a function of the change in muscle fibre CSA. Spearman's rank correlation coefficient $=0.98 \quad(P<0.001)$. Muscle fibres were cultured for 8 to 24 days muscle fibres cultured in the presence of BSA and those cultured in the presence of BSA + insulin.

PAS staining of cryosections of muscle fibres cultured in the presence of albumin exclusively or BSA + insulin show that glycogen contents in these muscle fibres were not different (Fig. 5d-f).

To investigate whether the hypertrophic muscle fibres excessively accumulated fatty acids, neutral lipid contents were investigated in freshly frozen muscles as well as in muscle fibres which had been cultured for at least 10 days in culture medium supplemented with BSA or BSA + insulin. In freshly frozen muscle cross sections, the absorbance of neutral lipid staining was related to the mitochondrial enzyme activities (data not shown). For low oxidative muscle fibres (SDH absorbance values ranging from 0.05 to 0.10 ), the oil red $\mathrm{O}$ absorbance increased with SDH activity from 0.01 to 0.05 . For the high oxidative muscle fibres (SDH absorbances varying from 0.10 to 0.31 ), the oil red $\mathrm{O}$ absorbances ranged from 0.03 to 0.08 . Interestingly, the muscle fibres which were cultured in the presence of BSA and BSA + insulin (mean SDH absorbance varying from 0.12 to 0.28 , see Fig. $5 \mathrm{j}-1$ ) showed considerably higher oil red $\mathrm{O}$ absorbance values ranging from 0.17 to 0.35 , which indicates that the muscle fibres synthesised and stored fatty acids during culture (Fig. 5g-i) but that final concentrations were the same for both culture conditions.

The mean SDH and CYTOX activity did not differ between muscle fibres cultured in the presence of BSA and those cultured in the presence of BSA + insulin (Fig. 5j-o).

The histological assays show that the increase in CSA and reduction in tetanic tension of fibres cultured in the presence of BSA + insulin were not due to excessive accumulation of cytoplasmic components and/or reduced myofibrillar ATPase activities.

\section{Discussion}

Albumin preserves E-C coupling

We investigated the effects of albumin on the survival of mature muscle fibres during long-term culture and whether albumin plays a role in the induction of hypertrophy. Albumin is shown to be important for the survival of isolated muscle fibres in serum-free culture medium. The present results show that for half of the muscle fibres cultured in medium supplemented with insulin exclusively, tetanic force upon electrical activation decreased by more than $50 \%$ during 1 week of culture, whereas caffeineinduced contractions yielded normal forces (i.e. similar to the initial values). As this has been shown also for freshly 

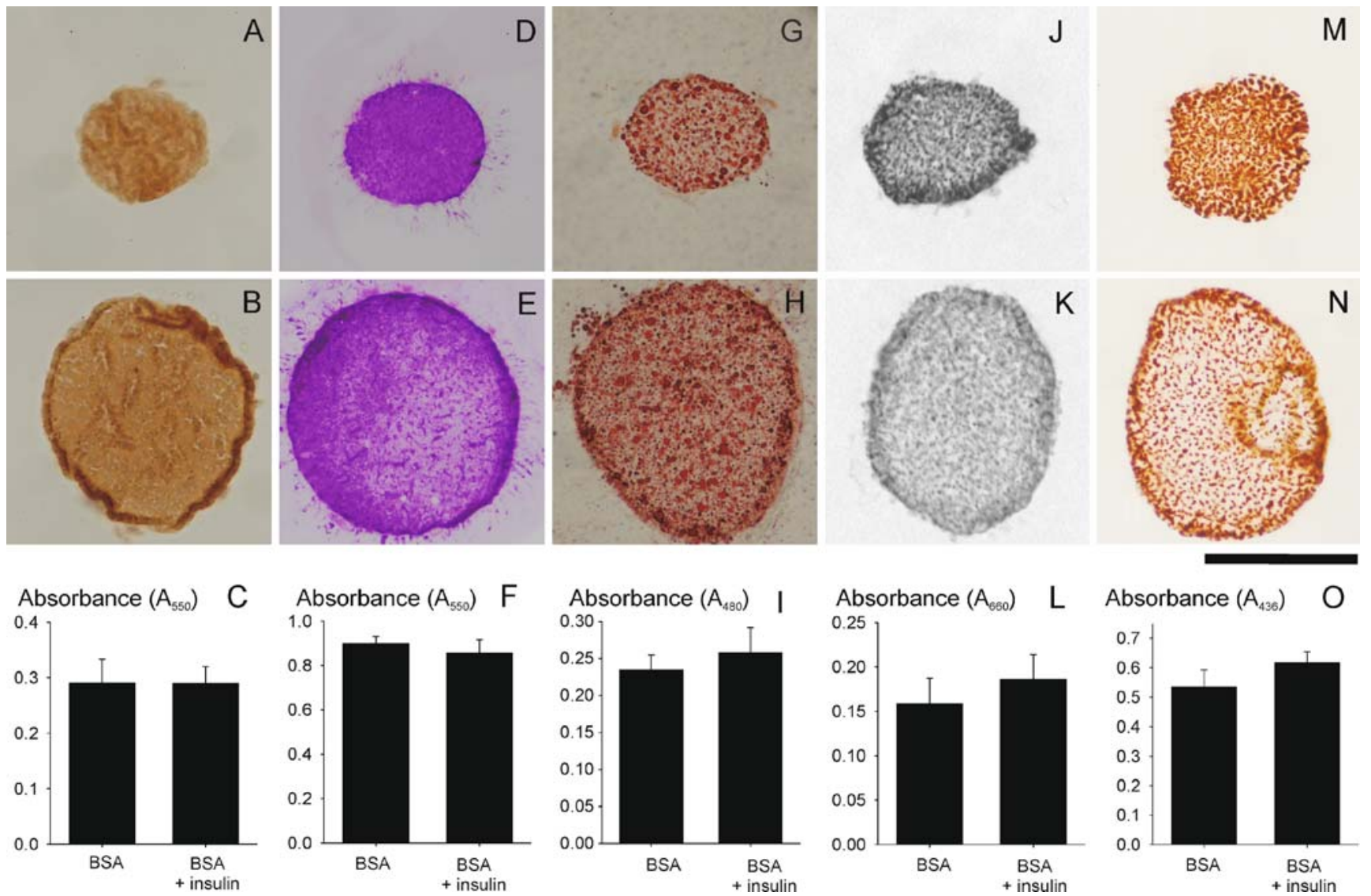

Fig. 5 Effects of albumin and insulin supplements on myofibrillar ATPase activity, cytoplasmic contents of neutral lipids and glycogen and SDH activity. The upper row of images (A, D, G, J and M) shows cross sections of a type 3 Xenopus muscle fibre cultured in medium with BSA only and the second row of images $(\mathrm{B}, \mathrm{E}, \mathrm{H}, \mathrm{K}$ and $\mathrm{N})$ that of a type $2 / 3$ fibre cultured in medium containing BSA + insulin. Note that for the fibre cultured in medium with BSA, the CSA decreased by $17 \%$, whereas for the fibre cultured in medium with BSA and insulin CSA increased by $38 \%$. Before culture, on the day of dissection the CSAs were 7,820 and $16,286 \mu^{2}$, respectively. a, b Myofibrillar ATPase staining of muscle fibre sections after culture in the presence of BSA and BSA + insulin. c The mean absorbance does not differ between conditions indicating that the increase in CSA is mainly due to an increase in the number of sarcomeres of the original type, arranged in parallel. d, e PAS staining of muscle fibre sections after culture in the presence of BSA and BSA + insulin. f Glycogen contents, determined by measurement of the absorbance $\left(\mathrm{A}_{550}\right)$, were

not different between conditions and were similar to those in freshly frozen muscle [52]. $\mathbf{g}, \mathbf{h}$ Neutral lipids contents after culture in the presence of BSA and BSA + insulin. i Fibre mean absorbance $( \pm$ SEM $)$ of the oil red $\mathrm{O}$ staining determined by measurement of the absorbance $\left(\mathrm{A}_{480}\right)$ does not differ between both conditions. The absorbance of the oil red $\mathrm{O}$ staining was corrected for the absorbance of the blank, determined in acetone-treated sections (mean absorbance $0.064 \pm 0.002)$. j, $\mathbf{k}$ SDH activity after culture in the presence of BSA and BSA + insulin. 1 After culture in medium with BSA or BSA + insulin, mean absorbance of the SDH stain was not different and was similar to the mean absorbance measured in type $2 / 3$ muscle fibre cross sections of three different freshly frozen muscles $\left(\mathrm{A}_{660}=0.17 \pm\right.$ $0.01) . \mathbf{m}, \mathbf{n}$ CYTOX activity after culture in the presence of BSA and $\mathrm{BSA}+$ insulin. o After culture in medium with BSA or BSA + insulin, mean absorbance of the CYTOX stain $\left(\mathrm{A}_{436}\right)$ was not different. Bar indicates $100 \mu \mathrm{m}$

dissected muscle fibres [33], these results suggest that the contractile apparatus of the in-excitable fibres was still functional and that the sarco-endoplasmic reticulum could still release $\mathrm{Ca}^{2+}$, but the ryanodine receptor could not be activated electrically. The question is raised by what mechanism albumin preserves $\mathrm{E}-\mathrm{C}$ coupling. In dog cardiac myocytes and rabbit slow skeletal muscle fibres, albumin acts as an antagonist of an endogenous inhibitor of the $\mathrm{Ca}^{2+}$-pumping activity of the SR in vitro [5]. However, in vivo, albumin has been localised in the interstitial space $[20,56]$ as well as in the T-tubular system but could not be detected in the cytoplasm [30, 9]. Therefore, an antagonistic, cytosolic effect on the inhibition of the $\mathrm{Ca}^{2+}$-pumping activity of the SR during culture can be debated. As albumin is a sacrificial antioxidant [18, 37], its binding to the sarcolemma may scavenge oxygen radicals and thereby protect it. As yet, it remains unclear by what mechanism albumin preserves the $\mathrm{E}-\mathrm{C}$ coupling and protects mature muscle fibres during culture. The substantial improvement of the survival and preservation of the E-C coupling of muscle fibres by albumin warrants further research in the protective mechanisms. 
Hypertrophy by synergy of insulin and albumin

In the presence of albumin, insulin has a strong hypertrophic effect on cultured muscles fibres (increase in fibre CSA of $>30 \%$ in 2 weeks), whereas insulin without albumin has not. Although the increase in muscle fibre CSA correlates with the increase in tetanic force, the increase in tetanic force was less than the increase in CSA. As a result, tetanic tensions of the fibres that hypertrophied decreased, whereas tensions of fibres that were cultured in medium supplemented with albumin exclusively increased. The discrepancy in magnitude of hypertrophy and change in peak tetanic force seems not explained by an increase in cytoplasmic components other than contractile proteins. For muscle fibres that showed an insulin-induced increase of CSA between $25 \%$ and $50 \%$, the glycogen content, as well as SDH and CYTOX activities increased during culture but at the end of culture the concentration and activities were not different between control and insulin-BSA-supplemented cultured muscle fibres and were similar to the concentrations measured in freshly frozen muscle [50, 52]. As for intact rabbit muscles, both SDH and CYTOX activities correlate with the mitochondrial density [43] and as SDH activities in intact Xenopus muscle fibres correlate with $\mathrm{VO}_{2 \max }$ [49], the increases in mitochondrial enzyme activities may indicate that BSA + insulin increased the biosynthesis of mitochondria. The neutral lipid concentrations in control and insulinsupplemented conditions were similar but substantially higher than those in freshly frozen muscle fibres. In addition, for cultured control and BSA + insulin-induced hypertrophic muscle fibres, the myofibrillar ATPase activity did not differ and was similar to those measured in freshly frozen sections [50]. Together, we conclude that the lower tetanic tensions of the hypertrophied muscle fibres cannot be explained by changes in the structural parametres studied.

In addition to its function in glycogen homeostasis in muscle, insulin regulates muscle protein synthesis and degradation via binding to the insulin or IGF-1 receptor $[17,53,29]$. Binding of insulin to the insulin-IGF-1 receptor activates the PI3K-Akt-mTOR pathway, which increases the rate of protein translation and inhibits the expression of E3 ubiquitin ligases [7, 34]. Furthermore, insulin and IGF-1 are also involved in the regulation of proliferation and differentiation of myoblasts and satellite cells $[11,15]$. The present finding that insulin exclusively does not induce hypertrophy of mature muscle fibres but does so in the presence of albumin indicates that hypertrophy of mature muscle fibres occurred via a synergistic effect of insulin and albumin. We assume that a synergistic effect of albumin and insulin has played a role in the insulin signalling in previous serum-based culture experiments as well as during in vivo experiments. The question remains by what mechanism albumin facilitates insulin signalling.
Albumin has been shown to be a protein and drug carrier $[57,37]$, but this function does not seem to be critical in vitro because insulin concentrations in the culture medium were at least thousandfold higher than in Xenopus blood plasma. In addition, it can be hypothesised that either insulin signalling via the insulin-IGF-1 receptor is more effective if insulin is bound to albumin and/or that albumin facilitates the binding of insulin with the insulin or IGF-1 receptor. Regarding the first possibility, the IGF-binding proteins in the extracellular matrix affect ligand-receptor interactions and signalling activities of IGFs in different cell types $[6,47]$. To the best of our knowledge, a direct role of albumin in insulin and IGF-1 signalling has not been indicated. Indirectly, pre-treatment of L6 skeletal muscle cells by glycated albumin has shown impaired insulininduced insulin receptor substrate phosphorylation in these cells [39], indicating that modified albumin can prevent proper binding of insulin with its receptor. In addition, for rat substrates, long-chain fatty acids have been indicated to modulate their biological activity [13, 41].

Regarding the second possibility, it can be hypothesised that albumin is involved in modulating the extracellular matrix of the muscle fibre, like that of endothelial cells. Albumin is a specific modulator of the glycocalyx, in particular of heparan sulfate, by preventing its collapse and by facilitating shear-loading-induced mechanotransduction in these cells $[48,24]$. As charges exposed by many proteins of the glycocalyx are mainly negative and albumin has both positive and negative charges at physiological $\mathrm{pH}$ [25], albumin could be involved in modulating the glycocalyx and insulin-IGF-1 signalling. During culture of muscle fibres in medium supplemented with insulin exclusively, the lack of insulin-induced hypertrophy may have been due to collapse of the proteoglycans at the basal lamina as suggested for endothelial cells, which may prevent binding of insulin to the insulin and/or IGF-1 receptors.

Whether albumin plays a role in the regulation of muscle fibre atrophy and hypertrophy in vivo remains to be determined. There are observations suggesting a role of albumin in the regulation of muscle size in vivo. Chronic low-frequency stimulation of rabbit tibialis anterior muscle causes an increase in interstitial albumin content [20]. Albumin contents in mice soleus muscle increased during different dis-use conditions [56]. Elevated albumin levels have been shown in dystrophic muscle of mdx mice [9]. In addition, lower serum albumin concentrations in elderly ( $>75$ years) are independently associated with a loss of muscle mass and strength (i.e. after adjustment for degree of physical activity, elevated inflammatory status and low protein intake) [3, 46, 54]. These results support our finding that albumin is crucial for insulin-induced muscle fibre hypertrophy. 
Adaptation of the number of sarcomeres in series

The present data indicate that insulin stimulates hypertrophy but does not increase the number of sarcomeres in series of muscle fibres in culture. Muscle fibres were cultured at a mean sarcomere length of $2.3 \mu \mathrm{m}$, which is slightly higher than the length at which actin and myosin show maximum overlap [16]. An important stimulus for in vivo adaptation of the number of sarcomeres in series is the length at which the muscle is operating most of the time (actively or passively) [21]. Immobilisations of rat and rabbit gastrocnemius medialis muscles at extended lengths strongly increase the expression of IGFs [58, 38]. As insulin can stimulate protein synthesis via the IGF-1 receptor, the lack of changes in the number of sarcomeres in series during culture in the presence of albumin + insulin suggests that other stimuli are required to increase the serial sarcomere number. This indicates that addition of sarcomeres is either induced by the combination of a high muscle strain and IGF-1-insulin, by paracrine signalling at the muscle fibre tendon, which may be ineffective in culture or that other biochemical and/or mechanical signals related to mechanical interactions with neighbouring muscle fibres by myofascial pathways are involved, which have been removed by the isolation of the muscle fibre [22].

In summary, we used a serum-free culture medium for long-term culture of mature single fibres to investigate effects of albumin and insulin under well-defined conditions. Supplements of albumin in serum-free culture medium are crucial to maintain fibres in good condition as it prevents muscle fibre damage and preserves the $\mathrm{E}-\mathrm{C}$ coupling. Furthermore, insulin-induced hypertrophy is critically dependent on albumin. We hypothesise that albumin facilitates the binding of insulin with the insulin and/or IGF-1 receptor.

Acknowledgments We thank students Lluis Millan Arino and Alba Jené Sanz for their support in histochemistry. This work was partially supported by research grants from the Haak Bastiaanse Kuneman Stichting and the Van Coeverden Adriani Stichting.

Open Access This article is distributed under the terms of the Creative Commons Attribution Noncommercial License which permits any noncommercial use, distribution, and reproduction in any medium, provided the original author(s) and source are credited.

\section{References}

1. Adachi R, Yabusaki K, Obinata T (2003) Uptake of albumin is coupled with stretch-induced hypertrophy of skeletal muscle cells in culture. Zool Sci 20:557-565

2. Bassel-Duby R, Olson EN (2006) Signaling pathways in skeletal muscle remodeling. Annu Rev Biochem 75:19-37
3. Baumgartner RN, Koehler KM, Romero L, Garry PJ (1996) Serum albumin is associated with skeletal muscle in elderly men and women. Am J Clin Nutr 64:552-558

4. Bland JM, Altman DG (1995) Calculating correlation coefficients with repeated observations: part 1 -correlation within subjects. BMJ 310:446

5. Chiesi M, Guerini D (1987) Characterization of heart cytosolic proteins capable of modulating calcium uptake by the sarcoplasmic reticulum. 1. Isolation of a protein with protective activity and its identification as muscle albumin. Eur J Biochem 162:365-370

6. Clemmons DR, Busby WH, Arai T, Nam TJ, Clarke JB, Jones JI, Ankrapp DK (1995) Role of insulin-like growth factor binding proteins in the control of IGF actions. Prog Growth Factor Res 6:357-366

7. Coolican SA, Samuel DS, Ewton DZ, McWade FJ, Florini JR (1997) The mitogenic and myogenic actions of insulin-like growth factors utilize distinct signaling pathways. J Biol Chem 272:66536662

8. De Castro M, Orive G, Gascon AR, Hernandez RM, Pedraz JL (2006) Evaluation of human serum albumin as a substitute of foetal bovine serum for cell culture. Int J Pharm 310:8-14

9. Dupont-Versteegden EE, Kitten AM, Katz MS, McCarter RJ (1996) Elevated levels of albumin in soleus and diaphragm muscles of mdx mice. Proc Soc Exp Biol Med 213:281-286

10. Favier FB, Benoit H, Freyssenet D (2008) Cellular and molecular events controlling skeletal muscle mass in response to altered use. Pflügers Arch DOI 10.1007/s00424-007-0423-z

11. Florini JR (1987) Hormonal control of muscle growth. Muscle Nerve 10:577-598

12. Florini JR, Ewton DZ, Coolican SA (1996) Growth hormone and the insulin-like growth factor system in myogenesis. Endocr Rev 17:481-517

13. Ghinea N, Eskenasy M, Simionescu M, Simionescu N (1989) Endothelial albumin binding proteins are membrane-associated components exposed on the cell surface. J Biol Chem 264:47554758

14. Glass DJ (2005) Skeletal muscle hypertrophy and atrophy signaling pathways. Int J Biochem Cell Biol 37:1974-1984

15. Goldspink G (2005) Impairment of IGF-I gene splicing and MGF expression associated with muscle wasting. Int $\mathrm{J}$ Biochem Cell Biol 37:2012-2022

16. Gordon AM, Huxley AF, Julian FJ (1966) The variation in isometric tension with sarcomere length in vertebrate muscle fibres. J Physiol (Lond) 184:170-192

17. Gulve EA, Dice JF (1989) Regulation of protein synthesis and degradation in L8 myotubes. Effects of serum, insulin and insulinlike growth factors. Biochem J 260:377-387

18. Halliwell B (1988) Albumin — an important extracellular antioxidant? Biochem Pharmacol 37:569-571

19. Harridge SDR (2007) Plasticity of human muscle: gene expression to in vivo function. Exp Physiol 92:783-797

20. Heilig A, Pette D (1988) Albumin in rabbit skeletal muscle. Origin, distribution and regulation by contractile activity. Eur $\mathrm{J}$ Biochem 171:503-508

21. Herring SW, Grimm AF, Grimm BR (1984) Regulation of sarcomere number in skeletal muscle: a comparison of hypotheses. Muscle Nerve 7:161-173

22. Huijing PA, Jaspers RT (2005) Adaptation of muscle size and myofascial force transmission: a review and some new experimental results. Scand J Med Sci Sports 15:349-380

23. Hurel SJ, Rochford JJ, Borthwick AC, Wells AM, Vandenheede JR, Turnbull DM, Yeaman SJ (1996) Insulin action in cultured human myoblasts: contribution of different signalling pathways to regulation of glycogen synthesis. Biochem J 320:871-877

24. Jacob M, Bruegger D, Rehm M, Loetsch M, Paul JO, Conzen P, Becker BF (2006) The endothelial glycocalyx prefers albumin for 
evoking shear-stress induced, NO mediated coronary dilatation. J Biomech 39:S92

25. Jacob M, Bruegger D, Rehm M, Stoeckelhuber M, Welsch U, Conzen P, Becker BF (2007) The endothelial glycocalyx affords compatibility of Starling's principle and high cardiac interstitial albumin levels. Cardiovasc Res 73:575-586

26. Jaspers RT, Feenstra HM, Lee-De Groot LM, Huijing PA, van der Laarse WJ (2001) Twitch and tetanic tension during culture of mature Xenopus laevis single muscle fibres. Arch Physiol Biochem 109:410-417

27. Jaspers RT, Feenstra HM, van Beek-Harmsen BJ, Huijing PA, van der Laarse WJ (2006) Differential effects of muscle fibre length and insulin on muscle-specific mRNA content in isolated mature muscle fibres during long-term culture. Cell Tissue Res 326:795808

28. Jaspers RT, Feenstra HM, Verheyen AK, Laarse WJ, Huijing PA (2004) Effects of strain on contractile force and number of sarcomeres in series of Xenopus laevis single muscle fibres during long-term culture. J Muscle Res Cell Motil 25:285-296

29. Kimball SR, Farrell PA, Jefferson LS (2002) Invited review: role of insulin in translational control of protein synthesis in skeletal muscle by amino acids or exercise. J Appl Physiol 93:1168-1180

30. Knudson CM, Campbell KP (1989) Albumin is a major protein component of transverse tubule vesicles isolated from skeletal muscle. J Biol Chem 264:10795-10798

31. Koopman R, Schaart G, Hesselink MK (2001) Optimisation of oil red $\mathrm{O}$ staining permits combination with immunofluorescence and automated quantification of lipids. Histochem Cell Biol 116:6368

32. Lännergren J, Smith RS (1966) Types of muscle fibres in toad skeletal muscle. Acta Physiol Scand 68:263-274

33. Lännergren J, Westerblad H (1989) Maximum tension and forcevelocity properties of fatigued, single Xenopus muscle fibres studied by caffeine and high K+. J Physiol 409:473-490

34. Latres E, Amini AR, Amini AA, Griffiths J, Martin FJ, Wei Y, Lin HC, Yancopoulos GD, Glass DJ (2005) Insulin-like growth factor1 (IGF-1) inversely regulates atrophy-induced genes via the phosphatidylinositol 3-kinase/Akt/mammalian target of rapamycin (PI3K/Akt/mTOR) pathway. J Biol Chem 280:2737-2744

35. Lee-de Groot MB, van der Laarse WJ (1996) Twitch characteristics and energy metabolites of mature muscle fibres of Xenopus laevis in culture. J Muscle Res Cell Motil 17:439-448

36. Liversage RA, Foty RA, Miles PD (1987) Serum immunoreactive insulin levels in intact and regenerating postmetamorphic Xenopus laevis. J Exp Zool 243:453-460

37. Matsushita S, Isima Y, Chuang VT, Watanabe H, Tanase S, Maruyama T, Otagiri M (2004) Functional analysis of recombinant human serum albumin domains for pharmaceutical applications. Pharm Res 21:1924-1932

38. McKoy G, Ashley W, Mander J, Yang SY, Williams N, Russell B, Goldspink G (1999) Expression of insulin growth factor-1 splice variants and structural genes in rabbit skeletal muscle induced by stretch and stimulation. J Physiol 516:583-592

39. Miele C, Riboulet A, Maitan MA, Oriente F, Romano C, Formisano P, Giudicelli J, Beguinot F, Van Obberghen E (2003) Human glycated albumin affects glucose metabolism in L6 skeletal muscle cells by impairing insulin-induced insulin receptor substrate (IRS) signaling through a protein kinase $\mathrm{C}$ alphamediated mechanism. J Biol Chem 278:47376-47387

40. Morley JE, Thomas DR, Wilson MM (2006) Cachexia: pathophysiology and clinical relevance. Am J Clin Nutr 83:735-743
41. Musters MW, Bassingthwaighte JB, van Riel NA, van der Vusse GJ (2006) Computational evidence for protein-mediated fatty acid transport across the sarcolemma. Biochem J 393:669-678

42. Old SL, Johnson MA (1989) Methods of microphotometric assay of succinate dehydrogenase and cytochrome c oxidase activities for use on human skeletal muscle. Histochem J 21:545-555

43. Pette D, Dusterhoft S (1992) Altered gene expression in fasttwitch muscle induced by chronic low-frequency stimulation. Am J Physiol 262:R333-R338

44. Rennie MJ, Wackerhage H, Spangenburg EE, Booth FW (2004) Control of the size of the human muscle mass. Annu Rev Physiol 66:799-828

45. Rothschild MA, Oratz M, Schreiber SS (1988) Serum albumin. Hepatology 8:385-401

46. Schalk BW, Deeg DJ, Penninx BW, Bouter LM, Visser M (2005) Serum albumin and muscle strength: a longitudinal study in older men and women. J Am Geriatr Soc 53:1331-1338

47. Stewart CE, Rotwein P (1996) Growth, differentiation, and survival: multiple physiological functions for insulin-like growth factors. Physiol Rev 76:1005-1026

48. Thi MM, Tarbell JM, Weinbaum S, Spray DC (2004) The role of the glycocalyx in reorganization of the actin cytoskeleton under fluid shear stress: a "bumper-car" model. Proc Natl Acad Sci U S A 101:16483-16488

49. van der Laarse WJ, Diegenbach PC, Elzinga G (1989) Maximum rate of oxygen consumption and quantitative histochemistry of succinate dehydrogenase in single muscle fibres of Xenopus laevis. J Muscle Res Cell Motil 10:221-228

50. van der Laarse WJ, Diegenbach PC, Hemminga MA (1986) Calcium-stimulated myofibrillar ATPase activity correlates with shortening velocity of muscle fibres in Xenopus laevis. Histochem J 18:487-496

51. van der Laarse WJ, Lannergren J, Diegenbach PC (1991) Resistance to fatigue of single muscle fibres from Xenopus related to succinate dehydrogenase and myofibrillar ATPase activities. Exp Physiol 76:589-596

52. van der Laarse WJ, van Noort P, Diegenbach PC (1992) Calibration of quantitative histochemical methods: estimation of glycogen content of muscle fibers using the PAS reaction. Biotech Histochem 67:303-308

53. Vandenburgh HH, Karlisch P, Shansky J, Feldstein R (1991) Insulin and IGF-I induce pronounced hypertrophy of skeletal myofibers in tissue culture. Am J Physiol 260:C475-C484

54. Visser M, Kritchevsky SB, Newman AB, Goodpaster BH, Tylavsky FA, Nevitt MC, Harris TB (2005) Lower serum albumin concentration and change in muscle mass: the Health, Aging and Body Composition Study. Am J Clin Nutr 82:531-537

55. Vollestad NK, Vaage O, Hermansen L (1984) Muscle glycogen depletion patterns in type I and subgroups of type II fibres during prolonged severe exercise in man. Acta Physiol Scand 122:433441

56. Wagatsuma A, Fujimoto K, Yamada S (2002) Alteration in albumin level during modified muscular activity. Scand J Med Sci Sports 12:143-149

57. Wunder A, Muller-Ladner U, Stelzer EH, Funk J, Neumann E, Stehle G, Pap T, Sinn H, Gay S, Fiehn C (2003) Albumin-based drug delivery as novel therapeutic approach for rheumatoid arthritis. J Immunol 170:4793-4801

58. Yang S, Alnaqeeb M, Simpson H, Goldspink G (1997) Changes in muscle fibre type, muscle mass and IGF-I gene expression in rabbit skeletal muscle subjected to stretch. J Anat 190:613-622 